\title{
DEPRIVATION, STAGE AT DIAGNOSIS AND CANCER SURVIVAL
}

\author{
Carola T.M. SCHRIJVERS ${ }^{1.4}$, Johan P. MACKENBACH', Jcan-Michel LuTZ², Michael J. QuinN ${ }^{3}$ and Michel P. ColeMAN ${ }^{2}$ \\ ${ }^{1}$ Department of Public Health, Erasmus University Medical School, Rotterdam, The Netherlands; ${ }^{2}$ Thames Cancer Registry, Sutton; \\ and ${ }^{3}$ Medical Statistics Division, Office of Population Censuses and Surveys, London, UK.
}

\begin{abstract}
The association between an area-based measure of deprivation and survival from the 10 most common cancers was studied in 155,682 patients diagnosed between 1980 and 1989 in the area covered by the South Thames Regional Health Authority. Furthermore, the impact of stage of disease at diagnosis on this association was studied. The measure of deprivation was the Carstairs Index of the census enumeration district of each patient's residence at diagnosis ( 5 categories) and the cancers studied were: lung, breast, colorectum, bladder, prostate, stomach, pancreas, ovary, uterus and cervix. In the univariate analyses the measure of outcome was the relative survival rate and in the multivariate analyses it was the hazard ratio. Both univariate and multivariate analyses showed that patients from affluent areas had better survival than patients from deprived areas for cancers of the lung, breast, colorectum, bladder, prostate, uterus and cervix. Stage of disease at diagnosis did not explain the survival differences by deprivation category. For cancers of the stomach, pancreas and ovary, no variation in survival by deprivation category was found. For most cancer sites, a clear gradient in survival by deprivation category was observed, which implies a large potential reduction of cancer mortality among the lower socioeconomic groups. Future studies need to incorporate other possible explanatory factors, besides stage, of the association between deprivation and survival.

(c) 1995 Wiley-Liss, Inc
\end{abstract}

The association between socioeconomic status and cancer mortality has been studied for many years (Logan, 1982). Attempts to explain the variation in cancer mortality rates between socioeconomic groups have mainly focused on studying socioeconomic variation in cancer incidence and the distribution of cancer-risk factors across groups. The variations in cancer survival and its possible determinants, for example, socioeconomic differences in the timing of cancer detection and treatment, have been studied less intensively (Kogevinas, 1990; Schrijvers and Mackenbach, 1994). Nevertheless, the potential for reduction of cancer mortality among the socioeconomically disadvantaged, by improving such factors as early detection and adequate treatment, seems promising, and socioeconomic variation in cancer survival should be monitored systematically. We therefore examined the association between an area-based measure of deprivation and cancer survival in the 10 most common cancers in the area covered by the South Thames Regional Health Authority (RHA).

The most recent studies that have dealt with the association between deprivation and survival in a large number of common cancers have not studied the impact of stage of disease at diagnosis on this association (Vågerö and Persson, 1987; Kogevinas et al., 1991). We were able to study the impact of stage of disease at diagnosis, an important prognostic factor, which may point to socioeconomic variation in the early detection of cancer.

\section{PATIENTS AND METHODS}

\section{Patients}

Data for this study came from the records of the Thames Cancer Registry, a population-based cancer registry covering a population of about 14 million people in south-east England. From 1960 to 1984 the registry covered the territory of the South Thames RHA; in 1985 coverage was extended to include the territory of the North Thames RHA. In this analysis, patients diagnosed from 1980 were studied and therefore only patients resident in South Thames RHA were included for study. The methods and data quality indices of the Registry have been described (Skeet, 1991) and incidence for the 1980s reported (Skeet et al., 1987; Chamberlain et al., 1993; Thames Cancer Registry, 1992a,b).

The records of all patients (men and women) diagnosed between 1980 and 1989 with a malignant tumour in one of the 10 most common cancer sites and aged 30 to 99 years at diagnosis were checked $(n=192,082)$. The cancers included were lung, breast, colorectum, bladder, prostate, stomach, pancreas, ovary, uterus and cervix. Two categories of patients were excluded from the analyses: patients with an incomplete or unknown postcode $(\mathrm{n}=11,495$ or $6 \%)$, since their census enumeration district could not be reliably determined (see below). The survival of these patients did not differ substantially from the survival of patients included in the analysis. Patients for whom the date of death was known but not the date of diagnosis (death certificate only cases, DCO) were also excluded from analyses, as their survival time could not be calculated $(n=24,905$ or $13 \%)$. A total of $155,682(81 \%$ of the original data set) were included in the survival analyses: 73,444 men and 82,238 women (Table I).

\section{Deprivation score}

The measure of deprivation for each patient was based on the address at time of diagnosis, by linking the full postcode of residence to the corresponding census enumeration district. Data from the 1981 census on 4 indicators of material deprivation were obtained for each enumeration district (average of 400 households in Great Britain): overcrowding (proportion of persons in private households living at a density of more than one person per room); male unemployment (proportion of economically active males seeking work); low social class (proportion of all persons in private households with head of household in social class IV or V); and car ownership (proportion of all persons in private households without a car).

The Carstairs Index combines standardized scores on these 4 variables into a single score for each census enumeration district (Carstairs and Morris, 1991), using the mean value and standard deviation for Great Britain as a standard.

Each of the 14,386 enumeration districts in South Thames RHA was assigned to one of 5 deprivation categories, which were constructed by ranking the Carstairs scores for all enumeration districts in Great Britain from low ("affluent") to high ("deprived"), and by forming quintiles based on the underlying population distribution.

\section{Prognostic factors}

Age was studied in 2 or 3 categories, depending on the age-distribution of cases for each cancer: lung, bladder and stomach (30-64, 65-74 and 75-99), breast, ovary, uterus and pancreas (30-64 and 65-99), colorectum and prostate (30-74 and 75-99), and cervix (30-44, 45-64 and 65-99). The results

${ }^{4}$ To whom correspondence and reprint requests should be sent, at: Department of Public Health, Erasmus University Medical School, PO Box 1738, 3000 DR Rotterdam. The Netherlands. Fax: +31 1043668 31.

Received: March 14, 1995 and in revised form July 12, 1995. 
TABLE I - NUMBER (PERCENTAGE) OF PATIENTS BY CANCER AND DEPRIVATION CATEGORY. 10 MOST COMMON CANCERS, MEN AND WOMEN, SOUTH THAMES RHA, 1980-1989

\begin{tabular}{lcccccc}
\multicolumn{7}{c}{ COMMON CANCERS, MEN AND WOMEN, SOUTH THAMES RHA, 1980-1989 } \\
\hline \multirow{2}{*}{ Cancer } & \multicolumn{7}{c}{$\begin{array}{c}\text { Deprivation category } \\
\text { (Affluent) }\end{array}$} & 2 & 3 & 4 & T & Total \\
\cline { 2 - 7 } & (Deprived) & \\
\hline Lung & $10,088(25.0)$ & $9,160(22.7)$ & $8,989(22.3)$ & $8,223(20.4)$ & $3,819(9.5)$ & 40,279 \\
Breast & $10,097(34.0)$ & $7,147(24.1)$ & $6,107(20.6)$ & $4,536(15.3)$ & $1,789(6.0)$ & 29,676 \\
Colorectum & $8,530(30.7)$ & $6,901(24.8)$ & $6,002(21.6)$ & $4,662(16.8)$ & $1,701(6.1)$ & 27,796 \\
Bladder & $3,896(30.1)$ & $3,065(23.7)$ & $2,809(21.7)$ & $2,282(17.6)$ & $905(7.0)$ & 12,957 \\
Prostate & $4,155(33.2)$ & $3,278(26.2)$ & $2,524(20.1)$ & $1,852(14.8)$ & $723(5.8)$ & 12,532 \\
Stomach & $2,828(25.9)$ & $2,560(23.4)$ & $2,414(22.1)$ & $2,200(20.1)$ & $929(8.5)$ & 10,931 \\
Pancreas & $1,979(29.2)$ & $1,666(24.6)$ & $1,438(21.2)$ & $1,203(17.8)$ & $486(7.2)$ & 6,772 \\
Ovary & $1,994(33.2)$ & $1,491(24.8)$ & $1,216(20.3)$ & $916(15.3)$ & $382(6.4)$ & 5,999 \\
Uterus & $1,537(30.9)$ & $1,261(25.4)$ & $1,064(21.4)$ & $775(15.6)$ & $331(6.7)$ & 4,968 \\
Cervix & $935(24.8)$ & $805(21.3)$ & $856(22.7)$ & $763(20.2)$ & $413(10.9)$ & 3,772 \\
Total & $46,039(29.6)$ & $37,334(24.0)$ & $33,419(21.5)$ & $27,412(17.6)$ & $11,478(7.4)$ & 155,682 \\
\hline
\end{tabular}

of analyses in which age was studied in much smaller categories did not differ from those presented in this report. Data for men and women were combined for cancers of the lung, colorectum, stomach and pancreas, as both overall survival and the gradient in survival by deprivation were very similar. Gender was included as a possible confounder for these cancers. Survival from bladder cancer was clearly higher for men than for women, therefore we will also discuss the results for this cancer for men and women separately. Period of diagnosis was included in the analysis in 25 -year periods: 1980 to 1984 and 1985 to 1989 . Stage at diagnosis (clinical or pathological) was explicitly stated in $20 \%$ of the medical records for all cancers combined. A simplified stage is routinely constructed by Registry staff for all cases, however, using pathology reports, operation notes and other information. Stage was originally categorized in 3 groups: local (tumour confined to the organ of origin); regional (involvement of regional lymph nodes) and metastasis (spread to distant organs). Patients for whom the stage at diagnosis was unknown were also included in the analysis as a fourth category. For most of the cancers, the percentage of patients diagnosed with a regional disease was rather low, and therefore the 4 categories of stage were distinguished only for cancers of the lung, breast, colorectum and stomach. For the other cancers, the distinction was local, non-local (regional and metastasis combined), and unknown. Data for cancers of the colon and rectum were combined, and adjustment was made for sub-site in 5 categories: (1) rectum, (2) sigmoid, (3) ascending colon, (4) transverse and descending colon, and (5) other sub-sites. Furthermore, sub-sites were distinguished for stomach cancer: (1) cardia, (2) pylorus, (3) stomach excluding cardia and pylorus.

\section{Survival analysis}

Cases diagnosed between 1980 and 1989 were followed up until the date of death or 31 December 1992, whichever occurred first.

To adjust for mortality from causes other than the cancer under study, we used the relative survival rate as measure of outcome in the univariate analyses. The relative survival rate, expressed as a percentage (RSR\%) is the ratio of observed survival in a group of cancer patients to the survival that would be expected if they were subject to the same overall mortality rates by age, gender and calendar period as the general population (Cutler and Ederer, 1958). The England and Wales life table for 1981 was used to calculate expected survival. The RSR and its $95 \%$ confidence interval (CI) were calculated by a computer program from the Finnish Cancer Registry (Hakulinen and Abeywickrama, 1985).

In the multivariate analyses, the measure of outcome was the hazard ratio which expresses the probability of death from the cancer under study for a specific category of patients relative to a reference category (which has a hazard ratio of unity). These analyses were conducted with a proportionalhazards model adapted to the RSR (Hakulinen and Tenkanen, 1987) using GLIM (Payne, 1985).

We started with a basic model which included duration of follow-up in 2 categories (up to 5 years, and 6 to 13 years) and deprivation category, and then added the other variables (age, gender, period of diagnosis, stage at diagnosis and sub-site for colorectal and stomach cancer). The improvement in fit due to each variable was tested for statistical significance at the $5 \%$ level with the Chi-square test. The statistical significance of the trend in the hazard ratio across deprivation categories was tested by examining the effect of adding deprivation category to the model as a continuous variable (one degree of freedom).

\section{RESULTS}

About $30 \%$ of all patients lived in areas categorized as the most affluent quintile of the Carstairs Index, while only $7.4 \%$ lived in areas categorized as the most deprived quintile. This distribution reflects the relative affluence of South Thames within Great Britain. For a few cancers, the percentage of patients in the 2 most affluent groups is higher than the percentage for all cancers combined: these are breast, prostate and ovary, and to a lesser extent colorectum and uterus. For cancers of the lung, stomach and cervix, the percentage of patients in the 2 most deprived categories is higher than the percentage for all cancers combined. For cancers of the bladder and pancreas, there was a similar distribution across deprivation categories as for all cancers combined. This variation in the distribution of patients across deprivation categories per cancer as compared with all cancers combined probably reflects variation in incidence by deprivation category (Table I).

Relative survival 5 years after diagnosis was better for patients from affluent areas than for patients from deprived areas for cancers of the lung, breast, colorectum, bladder, prostate, uterus and cervix. For these cancers we observed a gradient in survival by deprivation, which was interrupted in the second lowest category of deprivation for cancers of the lung, breast, prostate, uterus and cervix. The gradient in survival by deprivation for bladder cancer was present only in men (5-year RSR\%: affluent (1) 69, (2) 67, (3) 66, (4) 63, deprived (5) 62), but not in women. For cancers of the stomach, pancreas and ovary, no clear difference in 5-year RSR\% by deprivation category was observed (see Fig. 1 and Appendix).

For each of the cancers we saw a similar gradient in 10-year RSR\% by deprivation category as for the 5-year RSR\% (results not shown). For cancers with an overall 5-year RSR\% below 20 (pancreas, lung, stomach), we also examined the 

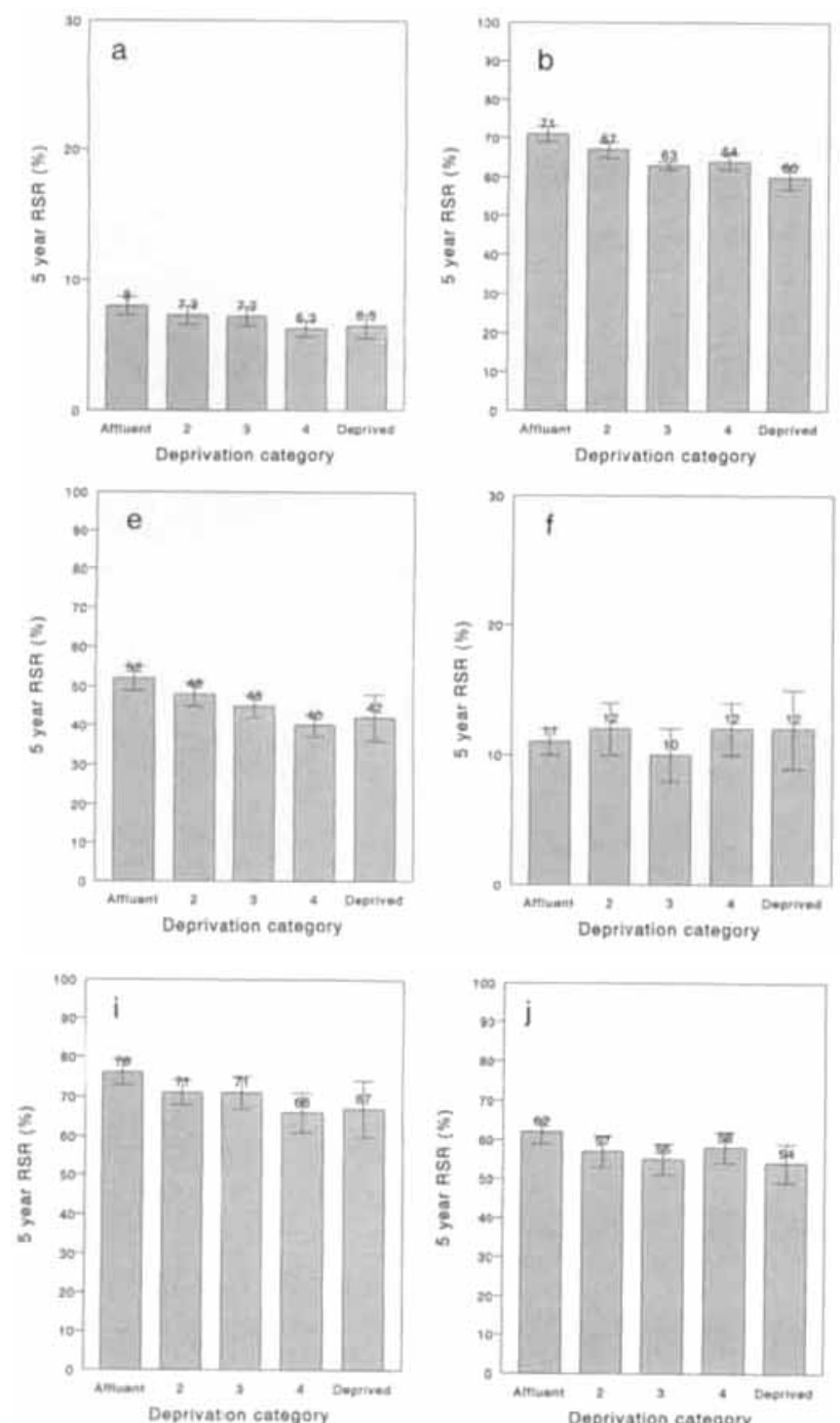
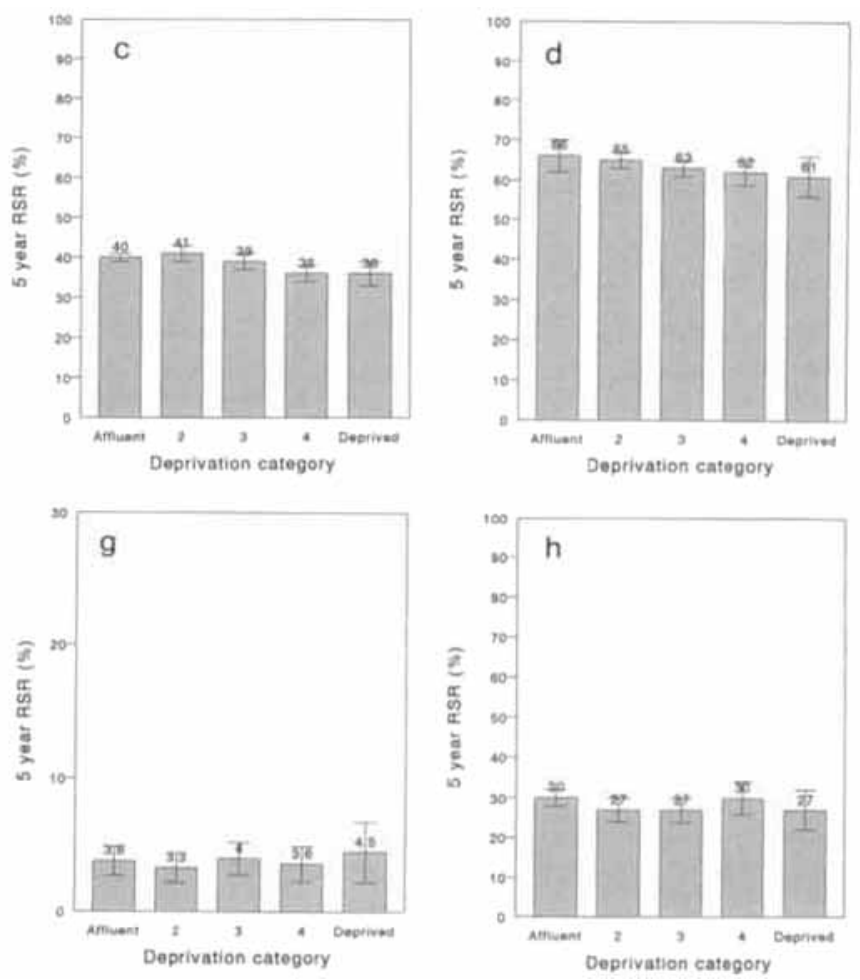

Figure 1 - Five-year relative survival rate (RSR\%), by cancer and deprivation category, 10 most common cancers, South Thames, 1980-1989. (a) Lung; (b) breast; (c) colorectum; (d) bladder; (e) prostate; $(f)$ stomach; $(g)$ pancreas; $(h)$ ovary; $(i)$ uterus; $(j)$ cervix.

\begin{tabular}{lccccc}
\multicolumn{2}{c}{ APPENDIX TABLE I - FIVE-YEAR RSR \% } & BY DEPRIVATION CATEGORY AND CANCER (SEE FIG. I) \\
\hline & $\begin{array}{l}\text { (Affluent) } \\
\text { Lung }\end{array}$ & 2 & 3 & 4 & 5 \\
(Deprived) \\
\hline Breast & 8.0 & 7.3 & 7.2 & 6.3 & 6.5 \\
Colorectum & 71 & 67 & 63 & 64 & 60 \\
Bladder & 40 & 41 & 39 & 36 & 36 \\
Prostate & 66 & 65 & 63 & 62 & 61 \\
Stomach & 52 & 48 & 45 & 40 & 42 \\
Pancreas & 11 & 12 & 10 & 3.6 & 12 \\
Ovary & 3.8 & 3.3 & 4 & 30 & 4.5 \\
Uterus & 30 & 27 & 27 & 66 & 27 \\
Cervix & 76 & 71 & 71 & 58 & 67 \\
\hline
\end{tabular}

survival gradient by deprivation, 1 and 2 years after diagnosis. For cancer of the pancreas, we observed a higher 1-year RSR\% in affluent patients than in deprived patients, but 2 years after diagnosis the gradient had disappeared. For lung and stomach cancer, the results for survival 1 and 2 years after diagnosis were similar to those for survival 5 and 10 years after diagnosis (results not shown).

The stage distribution by cancer and deprivation category showed no systematic pattern for most cancers. Only for breast cancer, and to a lesser degree for cancer of the prostate, we found a higher percentage of patients with non-local disease in the more deprived patient groups (Table II).

Table III shows the results from the multivariate analyses, by cancer and deprivation category. The hazard ratios presented in this table were adjusted for follow-up period, age, gender, period of diagnosis and sub-site in colorectal and stomach cancer. These hazard ratios combine results for the entire period of follow-up, so for example the hazard ratio of 1.13 for the most deprived category of lung-cancer patients means that during the entire period of follow-up, the annual 
TABLE II - PERCENTAGE OF PATIENTS WITH NON-LOCAL STAGE AT DIAGNOSIS BY CANCER AND DEPRIVATION CATEGORY, 10 MOST COMMON CANCERS. SOUTH THAMES RHA, 198(1-1989

\begin{tabular}{|c|c|c|c|c|c|c|}
\hline \multirow[b]{2}{*}{ Cancer } & \multicolumn{5}{|c|}{ Deprivation category } & \multirow[b]{2}{*}{ Total } \\
\hline & $\begin{array}{c}1 \\
\text { (Affluent) }\end{array}$ & 2 & 3 & 4 & $\begin{array}{c}5 \\
\text { (Deprived) }\end{array}$ & \\
\hline Lung & 30.3 & 30.9 & 29.1 & 28.9 & 29.3 & 29.8 \\
\hline Breast & 29.5 & 31.2 & 30.5 & 32.2 & 35.5 & 30.9 \\
\hline Colorectum & 32.6 & 33.2 & 32.6 & 31.9 & 32.2 & 32.6 \\
\hline Bladder & 4.6 & 4.7 & 5.1 & 5.1 & 4.8 & 4.8 \\
\hline Prostate & 26.8 & 26.3 & 28.3 & 27.8 & 31.4 & 27.4 \\
\hline Stomach & 37.3 & 36.7 & 36.4 & 36.5 & 35.3 & 36.6 \\
\hline Pancreas & 31.4 & 33.6 & 34.9 & 30.2 & 29.8 & 32.3 \\
\hline Ovary & 36.7 & 39.4 & 43.2 & 39.1 & 37.4 & 39.1 \\
\hline Uterus & 9.6 & 10.5 & 9.1 & 11.4 & 6.6 & 9.8 \\
\hline Cervix & 10.1 & 11.6 & 12.4 & 10.2 & 13.6 & 11.3 \\
\hline
\end{tabular}

excess probability of dying was $13 \%$ in the most deprived category as compared with the most affluent category (Table III).

The results from the multivariate analyses are in agreement with the results from the univariate analyses: the hazard ratios were higher in the more deprived categories for cancers of the lung, breast, colorectum, bladder, prostate, uterus and cervix. The trend in hazard ratios by deprivation was statistically significant for these cancers. For cancers of the stomach, pancreas and ovary, no clear gradient in hazard ratios by deprivation category was observed, and the trend in hazard ratios by deprivation was not statistically significant.

We tested the improvement of fit of the preceding model resulting from the addition of stage, which was statistically significant for each of the cancers. However, the addition of stage caused no large changes in the hazards for the 5 deprivation categories in most cancers (Table IV). The changes in hazard ratios for deprivation were largest for cancers of the uterus and cervix, especially in the most deprived patient group. For cervical cancer, the hazard ratio for the most deprived patient group changed from 1.35 to 1.27 and for cancer of the uterus from 1.46 to 1.59 .

\section{DISCUSSION}

Our results show that patients from deprived areas had worse survival than those from affluent areas for cancers of the lung, breast, colorectum, bladder, prostate, uterus and cervix, but not for cancers of the stomach, pancreas or ovary. The excess hazard of death for patients from the most deprived category ranged from $11 \%$ for colorectal and lung cancer to $59 \%$ for cancer of the uterus (adjusted for age, gender, period of diagnosis and stage at diagnosis). This shows an enormous potential for a reduction of cancer mortality by improving the survival rates of patients from deprived areas. Stage of disease at diagnosis was not an important explanatory factor of the association between deprivation and survival.

We considered a number of methodological aspects that might have influenced our results. First, we used an area-based measure of deprivation (Carstairs Index), which is a proxy measure of the deprivation of individual cancer patients. We did not use social class based on occupation as measure of deprivation, since this was incomplete or missing for a large proportion of patients, especially for women. Furthermore, deprivation was found to be more strongly associated with mortality than social class based on occupation (Carstairs and Morris, 1989). On the other hand, using an area-based measure could result in misclassification and therefore in underestimation of the gradient in survival by deprivation. For most cancers, our results were similar to those from another English study in which an individual measure of deprivation was used (Kogevinas et al., 1991). Better survival for patients with a low socioeconomic status was found in this study for cancers of the prostate, breast, and stomach and rectum in females. If the association between deprivation and survival for these cancers had been underestimated in our study as a result of misclassification, the findings from both studies on these cancers would be even more divergent.

Second, DCO cases were excluded from the analyses. However, the percentage of such cases varied systematically only across deprivation categories for lung cancer, with a higher DCO\% in more deprived categories (Table V). We were able to estimate the effect of DCO cases on observed lung-cancer survival, as the date of diagnosis of as many DCO cases as possible diagnosed during 1986-1987 had been obtained through the Family Health Service authorities. The survival of these cases could therefore be calculated and the ratio of survival reduction $(\%)$ to DCO $(\%)$ was used to estimate the impact of DCO bias on our results (J. Bullard, personal communication). The ratio of the observed 5-year survival rate in the most affluent group and the observed 5-year survival rate in groups 2 to 5 of lung-cancer patients respectively was $0.91,0.90,0.80$ and 0.85 . These ratios became 0.91 , $0.89,0.78$ and 0.81 , after correction for the exclusion of $\mathrm{DCO}$ cases, suggesting a small under-estimation of the deprivation by survival gradient in lung cancer after the exclusion of DCO cases.

Another possible source of bias is the use of a single life table, due to the absence of social-class-specific life tables, to calculate expected survival in order to adjust for mortality due to causes other than the cancer under study. This bias could have resulted in over-estimation of the gradient in relative survival by deprivation. In general, overall mortality is higher. in deprived areas, and therefore the expected survival of patients from more deprived groups may be over-cstimated if a life table from the general population is used. This may have resulted in under-estimation of the relative survival for the more deprived groups. For the affluent patient groups, expected survival may be under-estimated and relative survival over-estimated. There is some evidence, from a Finnish study on social class and breast-cancer survival, that this overestimation of the deprivation-survival gradient is rather small. The ratio of survival between the highest and lowest social class was 1.10 with corrected survival rates (censoring deaths from other causes) and 1.12 with relative survival rates (Karjalainen and Pukkala, 1990).

Furthermore, we considered the possibility that bias of the results arose from the use of a national rather than a regional life table to adjust for expected mortality. Overall mortality was lower in South Thames than in England and Wales as a whole (OPCS, 1987), so expected survival was lower and relative survival higher than if a regional life table had been used. It is unlikely, however, that differences in life expectancy calculated nationally or regionally would be systematic by deprivation category and therefore result in a bias of the relative survival gradient by deprivation.

Finally, the use of a life table based on a single year (1981) might have caused bias of the results, but this concerns overall survival. It seems unlikely that the association between deprivation and survival was biased, since the distribution of cases across years of diagnosis did not vary between deprivation categories.

The stage variable that we used in this analysis is not identical to the TNM stage. However, the resulting reduction in deviance was substantial in our analyses, suggesting reasonable validity of the stage variable. This was confirmed when the prognostic significance of this stage variable and the TNM stage were found to be very similar in breast-cancer cases for which both stage codes were available (J.-M. Lutz, personal communication).

We further considered the possibility that lead-time bias 
TABLE III - HAZARD RATIO (HR) AND 95\% CONFIDENCE INTERVAL (CI) BY CANCER AND DEPRIVATION CATEGORY, 10 MOST COMMON CANCERS, SOUTH THAMES RHA, 1980-1989

\begin{tabular}{|c|c|c|c|c|c|c|}
\hline \multirow[b]{2}{*}{ Cancer } & \multicolumn{5}{|c|}{ Deprivation category } & \multirow[b]{2}{*}{ Slope } \\
\hline & $\frac{1}{\text { (Affluent) }}$ & 2 & 3 & 4 & $\begin{array}{c}5 \\
\text { (Deprived) }\end{array}$ & \\
\hline & HR & $\operatorname{HR}(95 \% \mathrm{CI})$ & $\operatorname{HR}(95 \% \mathrm{CI})$ & $\mathrm{HR}(95 \% \mathrm{CI})$ & $\operatorname{HR}(95 \% \mathrm{CI})$ & $\operatorname{HR}(95 \% \mathrm{CI})$ \\
\hline Lung & 1.00 & $1.04(0.96-1.14)$ & $1.09(1.00-1.19)$ & $1.12(1.03-1.22)$ & $1.13(1.01-1.26)$ & $1.03(1.01-1.06)$ \\
\hline Breast & 1.00 & $1.15(1.02-1.30)$ & $1.27(1.12-1.44)$ & $1.27(1.11-1.46)$ & $1.47(1.22-1.76)$ & $1.09(1.06-1.13)$ \\
\hline Colorectum ${ }^{2}$ & 1.00 & $0.99(0.92-1.08)$ & $1.04(0.96-1.13)$ & $1.14(1.05-1.25)$ & $1.14(1.01-1.29)$ & $1.04(1.02-1.06)$ \\
\hline Bladder & 1.00 & $1.02(0.86-1.21)$ & $1.10(0.93-1.31)$ & $1.24(1.04-1.48)$ & $1.24(0.97-1.58)$ & $1.07(1.02-1.12)$ \\
\hline Prostate & 1.00 & $1.10(0.94-1.30)$ & $1.18(1.00-1.40)$ & $1.34(1.12-1.60)$ & $1.37(1.07-1.76)$ & $1.09(1.04-1.14)$ \\
\hline Stomach ${ }^{2}$ & 1.00 & $0.98(0.87-1.11)$ & $1.05(0.93-1.19)$ & $1.03(0.91-1.17)$ & $1.11(0.93-1.33)$ & $1.02(0.99-1.06)$ \\
\hline Pancreas & 1.00 & $1.01(0.88-1.15)$ & $0.96(0.83-1.11)$ & $1.07(0.92-1.25)$ & $1.04(0.84-1.28)$ & $1.01(0.97-1.05)$ \\
\hline Ovary & 1.00 & $1.10(0.91-1.34)$ & $1.13(0.93-1.39)$ & $1.05(0.84-1.31)$ & $1.10(0.81-1.50)$ & $1.02(0.97-1.08)$ \\
\hline Uterus & 1.00 & $1.21(0.90-1.61)$ & $1.18(0.87-1.60)$ & $1.48(1.09-2.02)$ & $1.46(0.97-2.20)$ & $1.11(1.02-1.20)$ \\
\hline Cervix & 1.00 & $1.15(0.94-1.40)$ & $1.29(1.07-1.57)$ & $1.17(0.96-1.44)$ & $1.35(1.07-1.71)$ & $1.06(1.01-1.12)$ \\
\hline
\end{tabular}

'Results from models with follow-up period, deprivation category, age, (gender), and period of diagnosis.-2Also adjusted for sub-site.

TABLE IV - HAZARD RATIO (HR) AND 95\% CONFIDENCE INTERVAL (CI) BY CANCER AND DEPRIVATION CATEGORY, 10 MOST COMMON CANCERS, SOUTH THAMES RHA, 1980-1989

\begin{tabular}{|c|c|c|c|c|c|c|}
\hline \multirow[b]{2}{*}{ Cancer } & \multicolumn{5}{|c|}{ Deprivation category } & \multirow[b]{2}{*}{ Slope } \\
\hline & $\begin{array}{c}1 \\
\text { (Affluent) }\end{array}$ & 2 & 3 & 4 & $\begin{array}{c}5 \\
\text { (Deprived) }\end{array}$ & \\
\hline & HR & $\mathrm{HR}(95 \% \mathrm{CI})$ & $\operatorname{HR}(95 \% \mathrm{CI})$ & $\mathrm{HR}(95 \% \mathrm{CI})$ & $\mathrm{HR}(95 \% \mathrm{CI})$ & $\mathrm{HR}(95 \% \mathrm{CI})$ \\
\hline Lung & 1.00 & $1.04(0.96-1.12)$ & $1.09(1.01-1.18)$ & $1.13(1.04-1.22)$ & $1.11(1.00-1.23)$ & $1.03(1.01-1.06)$ \\
\hline Breast & 1.00 & $1.15(1.06-1.25)$ & $1.29(1.19-1.41)$ & $1.24(1.13-1.36)$ & $1.43(1.27-1.62)$ & $1.09(1.06-1.11)$ \\
\hline Colorectum² & 1.00 & $1.02(0.95-1.09)$ & $1.03(0.96-1.11)$ & $1.16(1.07-1.25)$ & $1.11(1.00-1.24)$ & $1.04(1.02-1.06)$ \\
\hline Bladder & 1.00 & $1.05(0.91-1.22)$ & $1.07(0.93-1.25)$ & $1.22(1.05-1.42)$ & $1.22(0.99-1.51)$ & $1.06(1.02-1.10)$ \\
\hline Prostate & 1.00 & $1.11(0.99-1.25)$ & $1.21(1.07-1.36)$ & $1.37(1.20-1.56)$ & $1.34(1.12-1.60)$ & $1.09(1.06-1.13)$ \\
\hline Stomach ${ }^{2}$ & 1.00 & $0.98(0.87-1.10)$ & $1.04(0.93-1.18)$ & $1.02(0.90-1.15)$ & $1.11(0.93-1.32)$ & $1.02(0.99-1.05)$ \\
\hline Pancreas & 1.00 & $1.02(0.89-1.16)$ & $0.95(0.83-1.09)$ & $1.08(0.93-1.26)$ & $1.04(0.85-1.28)$ & $1.01(0.97-1.05)$ \\
\hline Ovary & 1.00 & $1.12(0.97-1.30)$ & $1.09(0.94-1.28)$ & $1.08(0.91-1.29)$ & $1.12(0.88-1.43)$ & $1.02(0.98-1.07)$ \\
\hline Uterus & 1.00 & $1.26(0.99-1.61)$ & $1.24(0.96-1.59)$ & $1.45(1.11-1.88)$ & $1.59(1.12-2.24)$ & $1.11(1.04-1.19)$ \\
\hline Cervix & 1.00 & $1.12(0.93-1.34)$ & $1.26(1.05-1.51)$ & $1.14(0.94-1.37)$ & $1.27(1.02-1.58)$ & $1.05(1.00-1.10)$ \\
\hline
\end{tabular}

${ }^{1}$ Results from models with follow-up period, deprivation category, age, (gender), period of diagnosis and stage.-2Also adjusted for sub-site.

TABLE V - DCO CASES (\%) BY CANCER AND DEPRIVATION CATEGORY, 10 MOST COMMON CANCERS, SOUTH THAMES RHA, 1980-1989

\begin{tabular}{lrrrrrr}
\multicolumn{1}{c}{ Cancer } & \multicolumn{1}{c}{ (Affluent) } & \multicolumn{1}{c}{2} & \multicolumn{1}{c}{3} & 4 & $\begin{array}{c}5 \\
\text { (Deprived) }\end{array}$ & Total \\
\cline { 1 - 5 } Lung & 15.8 & 16.2 & 17.3 & 18.3 & 19.9 & 17.2 \\
Breast & 7.9 & 8.9 & 9.0 & 9.4 & 9.4 & 9.4 \\
Colorectum & 14.1 & 13.3 & 13.3 & 12.9 & 15.9 & 13.6 \\
Bladder & 6.8 & 6.5 & 5.7 & 7.8 & 7.4 & 6.7 \\
Prostate & 12.2 & 12.7 & 13.5 & 12.5 & 13.5 & 12.7 \\
Stomach & 19.9 & 17.6 & 17.8 & 18.9 & 21.8 & 18.9 \\
Pancreas & 22.5 & 20.1 & 20.8 & 21.1 & 20.3 & 21.1 \\
Ovary & 11.4 & 11.9 & 13.4 & 13.2 & 12.8 & 12.3 \\
Uterus & 5.9 & 6.2 & 5.6 & 5.7 & 8.3 & 6.0 \\
Cervix & 5.9 & 5.7 & 5.5 & 7.6 & 4.8 & 6.0 \\
\hline
\end{tabular}

might explain part of the survival with deprivation gradient in this study. The analyses in this paper included an adjustment for stage of disease at diagnosis. As the period between origin of the tumour and diagnosis is associated with stage, adjustment was made, indirectly, for lead-time. Of course, residual confounding due to stage, and therefore lead-time, may still explain part of the association between deprivation and survival. However, if lead-time bias were the explanation, we would expect a larger difference in survival by deprivation in the first period of follow-up than in the later period, and this was clearly not the case in our study. The results from survival analyses of patients with metastatic disease showed better survival for patients from the most affluent group as compared with the most deprived group for 6 out of the 7 cancers for which we had observed better survival in the affluent patients; the only exception was lung cancer. However, the gradient in survival by deprivation was not consistent for any of these cancers and $95 \%$ CIs were rather broad for most categories.

Only for cancers of the cervix and uterus did we find a substantial change in the hazard ratios for the 5 deprivation categories resulting from the addition of stage. Although stage is a very important prognostic factor in general, it cannot explain the gradient in survival by deprivation. This was also found in other studies, in which socioeconomic variation in survival from either breast cancer (Karjalainen and Pukkala, 1990; Bassett and Krieger, 1986; Gordon et al., 1992) colorectal cancer (Wegner et al., 1982; Brenner et al., 1991), colon cancer (Auvinen, 1992) or cancer of the prostate (Dayal et al., 1985) persisted after adjustment for stage. Similar results were found in older studies for many cancer sites (Linden, 1969; Lipworth et al., 1970; Berg et al., 1977).

Another possible explanation for the gradient in survival by deprivation is a difference in the management of cancer patients from various deprivation categories. It could be argued that this factor may be more important in cancers with an overall medium or good prognosis, and that for such cancers socioeconomic variation in survival would be larger. We calculated the ratios of survival rates of the most affluent and the most deprived patient group for each cancer and ranked these according to overall survival of the cancers. From these results we observed no clear gradient, which is in agreement with other results (Kogevinas, 1990). We did find, however, that the variation in survival by deprivation was absent or rather small in cancers with relatively poor or moderate overall survival (pancreas, lung, stomach, ovary, colorectum), while variation was larger in cancers with a fairly high overall survival (prostate, bladder, cervix, breast, uterus). 
Our results show that the gap in survival between cancer patients from affluent and deprived areas is large, both in absolute and relative terms. We found no evidence for an explanation of the survival gradient by deprivation in terms of large variation in stage of disease at diagnosis. Other determinants of socioeconomic variation in early detection of cancer by deprivation should be studied, such as the biological aggressiveness of a tumour, and host factors which may interact with the tumour. Examples of such factors are comorbidity, psychological factors, nutritional status, social sup- port, and immune response. In addition, determinants of treatment should be studied, such as adherence to guidelines and type of hospital.

\section{ACKNOWLEDGEMENTS}

C.T.M.S. was supported by a grant from the Research and Development programme of South-West Thames Regional Health Authority.

\section{REFERENCES}

Auvinen, A., Social class and colon cancer survival in Finland. Cancer, 70, 402-409 (1992).

Basset, M.T. and Krieger, N., Social class and black-white differences in breast-cancer survival. Amer. J. publ. Hith., 76, 1400-1403 (1986).

BerG, J.W., Ross, R. and Latourette, H.B., Economic status and survival of cancer patients. Cancer, 39, 467-477 (1977).

Brenner, H., Mielck, A., Klein, R. and Ziegler, H., The role of socioeconomic factors in the survival of patients with colorectal cancer in Saarland/Germany. J. clin. Epidemiol., 44, 807-815 (1991).

Carstalrs, V. and Morris, R., Deprivation and mortality: an alternative to social class? Comm. Med., 11, 210-219 (1989).

Carstairs, V. and Morris, R., Deprivation and health in Scotland, Aberdeen University Press, Aberdeen (1991).

Chamberl.ain, J., Bourne, H.M. and Thornton-Jones, H., UK, England, South Thames Regions, 1983-1987. In: D.M. Parkin, C.S. Muir, S.L. Whelan, Y.-T. Gao and J. Powell (eds.), Cancer incidence in five continents, Vol. VI, pp. 790-793, IARC Scientific Publication 120, IARC, Lyon (1993)

Cutler, S.J. and Ederer, F., Maximum utilization of the life-table method in analyzing survival. J. chron. Dis., 8, 699-712 (1958).

Dayal. H.H., Polissar, L. and Dahlberg, S., Race, socioeconomic status, and other prognostic factors for survival from prostate cancer. $J$. Natl. Cancer Inst., 74, 1001-1006 (1985).

Gordon, N.H., Crowe, J.P., Brumberg, D.J. and Berger, N.A., Socioeconomic factors and race in breast-cancer recurrence and survival. Amer. J. Epidemiol., 135, 609-618 (1992).

Hakulinen, T. and ABEYwickrama, K.H., A computer program package for relative survival analysis. Comp. Prog. Biomed., 19, 197-207 (1985).

Hakulinen, T. and Tenkanen, L., Regression analysis of relative survival rates. Appl. Statist., 36, 309-317 (1987).

Karjalainen, S. and Pukkala, E., Social class as a prognostic factor in breast-cancer survival. Cancer, 66, 819-826 (1990).

KogEvinas, E., Longitudinal study. Socio-demographic differences in cancer sumival. OPCS Series LS 5, HMSO, London (1990).

Kogevinas, M.. Marmot, M.G., Fox, A.J. and Goldblatt, P.O.,
Socioeconomic differences in cancer survival. J. Epidemiol. Community Hlth., 45, 216-219 (1991).

LINDEN, G., The influence of social class in the survival of cancer patients. Amer. J. publ. Hlth., 59, 267-274 (1969).

Lipworth, L., ABElin, T. and CONNElly, R.R., Socioeconomic factors in the prognosis of cancer patients. I. chron. Dis., 23, 105-116 (1970)

LOGAN, W.P.D., Cancer mortality by occupation and social class 1851-1971. IARC Scientific Publication 36, Studies on Medical and Population Subjects, 44, HMSO, London; IARC, Lyon (1982).

OPCS, Montality statistics: area, 1985. Series DH5 12. HMSO, London (1987).

PAYNE, C.D., The GLIM system release 3.77. Generalized linear interactive modelling manual. Numerical Algorithms Group, Oxford (1985).

SChrijvers, C.T.M. and MaCKenbach, J.P., Cancer-patient survival by socioeconomic status in seven countries: a review for six common cancer sites. J. Epidemiol. Community Hith., 48, 441-446 (1994).

SkEET, R.G., The Thames Cancer Registry. In: O.M. Jensen, D.M Parkin, R. MacLennan, C.S. Muir and R.G. Skeet (eds.), Cancer registration: principles and methods, pp. 237-245. IARC Scientific Publication 95, IARC, Lyon (1991).

SkeEt, R.G., Thornton-Jones, H. and Murrells, T.J., UK, England, South Thames Regions, 1978-1982. In: C.S. Muir, J.A.H. Waterhouse T. Mack, J. Powell, S.L. Whelan (eds.), Cancer incidence in five continents, Vol. V, pp. 664-667, IARC Scientific Publication 88, IARC, Lyon (1987).

Thames Cancer Registry, Cancer in South-East Thames, 1987-1989. cancer incidence, prevalence and survival in residents of the Distric Health Authorities in South-East Thames. Thames Cancer Registry. Sutton (1992a).

Thames CAnCER Registry, Cancer in South-West Thames, 1987-1989. cancer incidence, prevalence and survival in residents of the District Health Authorities in South-East Thames. Thames Cancer Registry Sutton (1992b)

VÅgerö, D. and Persson, G., Cancer survival and social class in Sweden. J. Epidemiol. Community Hlth., 41, 204-209 (1987).

Wegner, E.L., Kolonel, L.N., Nomura, A.M.Y. and LeE, J., Racial and socioeconomic status differences in survival of colorectal-cancer patients in Hawaii. Cancer, 49, 2208-2216 (1982). 